|| Print ISSN: 2589-7837 || Online ISSN: 2581-3935 ||

International Journal of Medical Science and Diagnosis Research (IJMSDR)

Available Online at www.ijmsdr.com

NLM (National Library of Medicine ID: 101738824)

\title{
Microflora Responsible for Failure of RCT : A Review
}

\section{Dr. Anil K Tomer ${ }^{1}$, Dr. Nivedita Saini², Dr. Shivangi Jain ${ }^{3}$, Dr. Geetika Sabharwal ${ }^{4}$, Dr. Ayan Guin ${ }^{5}$}

\author{
${ }^{1}$ Professor and Head, Department of Conservative Dentistry and Endodontics, Divya Jyoti \\ College of Dental Sciences and Research, Modinagar, Uttar Pradesh. \\ ${ }^{2-5}$ Postgraduate students, Department of Conservative Dentistry and Endodontics, Divya \\ Jyoti College of Dental Sciences and Research, Modinagar, Uttar Pradesh.
}

\author{
Conflicts of Interest: Nil \\ Corresponding author: Dr. Nivedita Saini \\ DOI: https://doi.org/10.32553/ijmsdr.v6i1.908
}

\begin{abstract}
:
Endodontic treatment failure can be caused by a variety of factors, including bacterial persistence, improperly cleaned and obturated root canals, faulty coronal seal (leakage), and untreated canals (missed canals). The presence of bacteria such as Enterococcus (E.) faecalis inside the root canal system is the most common cause of endodontic failure. These bacteria are more resistant to disinfectants, resulting in an infection that persists intra-radicularly or extra-radicularly. Many other microorganism are also responsible for failure of root canal treatment, resulting in endodontic flare-up .

This review article will discuss about the causes of failure of root canal treatment ,pathogenesis and strategies by which microbes persist in root canal, method of eradication of such microorganism and management of such cases.
\end{abstract}

Keywords: Enterococcus, Enterococcus

\section{Introduction:}

In recent years due to significant refinements in the delivery of endodontic services and various advancements in the field, both professional and public expectations for the successful retention of natural dentition has increased.

Endodontic treatment is fairly predictable in nature with reported success rates up to 86$98 \%$. However, along with these successful root canal treatments there comes inevitable percentage of non healed and endodontic failures where in some instances root canal treatment is not fully successful in elimination of signs and symptoms of the cause of root canal treatment.
In majority of endodontic outcome studies the outcome assessment is based on clinical and radiographic measures. The successful outcome is defined by complete absence of clinical signs and symptoms and radiolucency. To determine the success of an endodontically treated tooth, the tooth should be evaluated clinically and radiographically for its root canal at successive follow-up appointments.

Like variable definitions for a successful outcome of endodontic treatment, "failure" of endodontic treatment has variations.

To understand the cause of failure of endodontic treatment it is important to completely understand the microbiology 
involved in the endodontic pathology. This will help us to modify the conventional treatment plans and effectively combat the microorganisms. Now-a-days, studies are aiming to explore the characteristics of the "most" resistant organism to the conventional methods of instrumentation and disinfection of the root canal space and the methods to improve the techniques of root canal disinfection to completely eradicate different components of pulpal tissue, bacteria and biofilm and produce a hermetic seal.

\section{Causes of failure of root canal treatment}

The cause of failure of root canal treatment can be either due to persistence of some bacteria's in the root canal even after thorough cleaning and shaping of the root canal or due to secondary infection of the root-filled teeth. Generally, it is accepted that persistence of disease in periapical tissues is most commonly associated with a difficulties or misshapes which occur during or after initial endodontic treatment. Inadequate aseptic control, poor access cavity design, missed canals, inadequate instrumentation and leaking temporary or permanent restorations are the main factors that may be critically important in posttreatment disease. Persisting bacteria in root canals may be those originally present in the necrotic pulps that survive the biomechanical procedures, which may be located in missed canals or uninstrumented areas of the canals. Some species of microorganisms found in such failure cases are capable to survive under harsh, nutrient-limited conditions of the root filled canal.

Based on numerous studies four main factors which may contribute to persistence of a periapical radiolucency after treatment have been detected. These are:

1) intraradicular infection

2) extraradicular infection

3) foreign body reaction
4) cysts

\section{PATHOGENESIS OF APICAL PERIODONTITIS}

Apical periodontitis is an infectious disease having a polymicrobial etiology and the bacterial community profiles which significantly vary from subject to subject.

For a better understanding of the microbiological goals of endodontic treatment of teeth with apical periodontitis, the following discussion relies on the classical observations of Theobald Smith that an infectious disease is the result of the interplay between microbial virulence and number (load) and the host defenses.

Contextually, this concept combined with recent data on microbial community behavior, quorum- sensing mechanisms and virulence regulation can be applied to the understanding of the pathogenesis of apical periodontitis as an infectious disease and, consequently, can serve as a rationale for setting the goals clinicians should pursue during treatment.

It is well recognized that for any bacterial species to cause disease, they have to reach a population density (load) that is conducive to tissue damage either caused by the bacteria themselves or by the host defense mechanisms in response to infection.

Before a quorum of bacterial cells is reached in the infected site, no clinical signs and symptoms of the disease are apparent.

Conceivably, the number of cells sufficient to cause disease is inversely proportional to virulence, ie, the higher the bacterial virulence the lower the number of cells necessary to cause disease. Because endodontic infections are characterized by mixed populations of about 10 to 20 species with varying levels of virulence, it is virtually impossible to ascertain the threshold beyond which the number of cells is sufficient to induce disease. 
Host resistance is another important factor that impacts on disease pathogenesis. The same combination of bacterial species at the same counts may give rise to different responses in different individuals.

With this concept of bacterial load in mind, it is easy to understand the effects of treatment on the outcome of infection. Ideally, endodontic treatment procedures should sterilize the root canal which means it should eliminate all living microorganisms present in the entire root canal system.

However, given the complex anatomy of the system, it is widely recognized that, with available instruments, substances, and techniques, fulfilling this goal is otherwise utopic for most cases. Therefore, the reachable goal is to reduce bacterial populations to a level below that necessary to induce or sustain disease.

\section{PERSISTENCE OF BACTERIA IN ROOT CANAL:}

It is important to understand some aspects related to the significance of bacteria found in post-treatment samples.

It is important to be aware of the time that bacterial "persisters" are detected in treated canals. Studies of the bacteria occurring in the root canal after treatment approaches involve three basic conditions:

1. postinstrumentation samples (collected immediately after completion of chemomechanical procedures)

2. postmedication samples (collected immediately after the removal of interappointment dressings)

3. postobturation samples (collected from root canal-treated teeth with associated apical periodontitis lesion at a given time, months to years after treatment)

Studies investigating bacteria remaining in the root canals after chemomechanical procedures or intracanal medication serve the purpose to disclose the species that have the potential to influence the treatment outcome.

On the other hand, studies dealing with the microbiota of root canal-treated teeth evincing apical periodontitis serve to show the association of species with treatment failure because the microorganisms detected are likely to be participating in the etiology of persistent disease.

Even when the endodontic treatment does not succeed in completely eradicating the infection, the huge majority of bacteria are eliminated and the environment is markedly disturbed.

To survive and therefore be detected in post treatment samples, bacteria have to resist or escape intracanal disinfection procedures and rapidly adapt to the drastically altered environment caused by treatment procedures.

Bacteria detected in postinstrumentation samples are remainders of the initial infection that resisted the effects of instruments and irrigants or were introduced in the root canal as a result of a breach in the aseptic chain.

Whatever the source, detected bacteria are temporary "persisters" that have not yet had enough time to adapt to the new environment, which has been changed by chemomechanical procedures. Their survival and involvement with treatment outcome will be reliant on the adaptation ability.

The application of an antimicrobial intracanal medication may be the "mercy killing" for remaining bacteria. Bacteria detected in postmedication samples are ones which have survived both chemomechanical procedures and intracanal medication or gained entry into the root canal via leakage through the temporary restoration. Based on the time of sampling, these bacteria have had allegedly more time for adaptation to the modified environment. Bacteria found in postobturation samples of teeth indicated for retreatment because these are conceivably adapted to the 
new environment and are remainders of a primary infection that resisted treatment procedures or penetrated in the root canal after filling via coronal leakage (reinfection). In these cases, failure is already established,

\section{STRATEGIES TO PERSIST BY MICROBES IN ROOT CANAL}

For bacteria to endure treatment and be detected in post treatment samples, they must

(1) resist intra canal disinfection procedures

(2) adapt to the drastically changed environment

Several strategies may help bacteria to resist treatment. Bacteria can adhere to the root canal walls, accumulate, and form communities organized in biofilms, which can be important for bacterial resistance to and persistence after intracanal antimicrobial procedures.

Bacteria located in ramifications, isthmi, and other irregularities are likely to escape the effects of instruments (because of physical limitations) and irrigants (because of time constraints) used during chemomechanical procedures. The ability of some bacteria to penetrate dentinal tubules, sometimes to a deep extent, can also enable them to escape from the action of instruments and substances used during treatment.

Antimicrobial medicaments used in endodontics can be in- activated by dentin, tissue fluids, and organic matter. Some microbial species, such as E. faecalis and Candida albicans, can show resistance to calcium hydroxide, a commonly used intracanal medicament.

In addition to escaping from treatment procedures, adaptation to the new environment is crucial for residual bacteria to cause persistent disease. A major change in the environment induced by treatment is related to a dramatic reduction in nutrient availability. The fact that the huge majority of root canaltreated teeth with posttreatment apical periodontitis have been shown to harbor an intraradicular infection indicates that microorganisms can in someway acquire nutrients within filled root canals.

Because virtually all micro leakage studies have shown that no root canal-filling technique or material succeeds in promoting a fluid-tight coronal and apical seal of the root canal, residual microorganisms can derive nutrients from saliva (coronally seeping into the root canal) or from periradicular tissue fluids and inflammatory exudate (apically or laterally seeping into the root canal). Even though most necrotic pulp tissue is removed during chemo-mechanical procedures, remaining bacteria can also use necrotic tissue remnants as a nutrient source.

Tissue remnants can be localized in isthmi, irregularities, dentinal tubules, and lateral canals, which very often remain unaffected by instruments and irrigants. In addition, even in the main canal, some walls can remain untouched after instrumentation. Although pulp tissue remnants comprise only a temporary source of nutrients, they can maintain bacterial survival before a sustainable source of nutrients is established by apical or coronal leakage.

The fact that nutrients must exist but they are substantially reduced in amount suggests that, in order to survive, residual bacteria have to develop strategies to deal with famine. Environmental cues can regulate gene expression in bacteria, enabling them to adapt to varying environmental conditions. For instance, several regulatory systems play essential roles in the ability of bacteria to withstand nutrient depletion. These systems are under the control of determined genes whose transcription is activated under conditions of starvation.

For instance, under conditions of nitrogen starvation, the activation of the Ntr gene system enables bacteria that require ammonia as a nitrogen source to scavenge even 
small traces of ammonia. Under high concentration of ammonia, the Ntr gene system is uncoupled. Under low concentrations of glucose, some bacteria can activate the catabolite repressor system, under control of the genes cya (adenylate cyclase) and crp (catabolite repressor protein), which induce the synthesis of enzymes for the utilization of various other organic carbon sources. Under conditions of phosphate starvation triggered by low concentrations of inorganic phosphate, cells turn on genes for the utilization of organic phosphate compounds and for the scavenging of trace amounts of inorganic phosphate.

Another way to deal with changing environmental conditions is through the production of stress proteins.Exposure to environmental stresses may affect bacterial survival and induce accumulation of damaged or denatured proteins. In response, bacteria can induce or accelerate the synthesis of specific proteins known as stress proteins, including heatshock proteins, which are families of highly conserved proteins whose main role is to allow microorganisms to survive under stressful conditions. Heat-shock proteins act as molecular chaperones in the assembly and folding of proteins and as proteases when

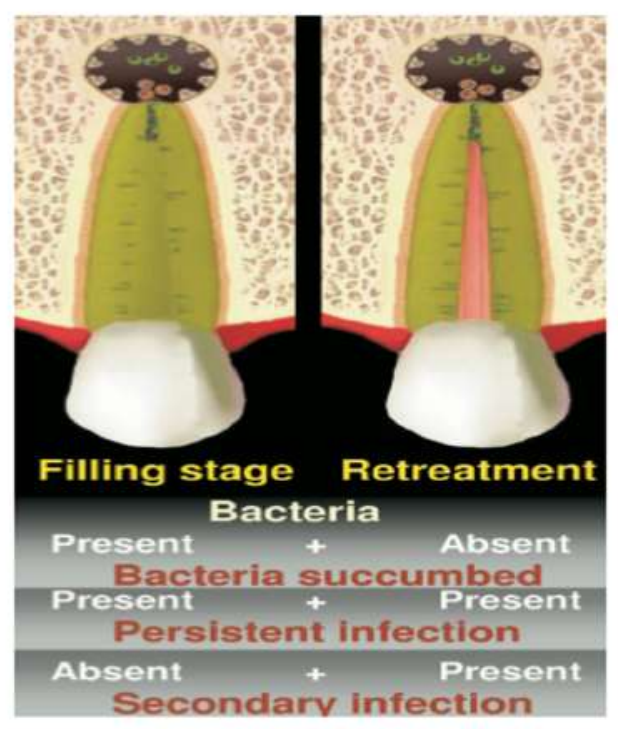

damaged or toxic proteins have to be degraded. Several pathological functions have been associated with these proteins, including cytotoxicity that may contribute to tissue destruction.

It has been shown that some bacteria, such as E. faecalis, can enter a viable but noncultivable state, which is a survival mechanism adopted by many bacteria when exposed to adverse environmental conditions, including low nutrient concentrations, high salinity, and extreme pH.64 In a viable but noncultivable state, bacteria lose the ability to grow in culture media but maintain viability and pathogenicity and sometimes are able to resume division when favorable environmental conditions are restored.

E. faecalis has the ability to survive in environments with scarcity of nutrients and to flourish when the nutrient source is reestablished. Through various studies E. faecalis has the capacity to recover from a prolonged starvation state in root canal-treated teeth; when inoculated into the canals, this bacterium maintained viability for 12 months without additional nutrients. Thus, viable E. faecalis entombed at the time of root canal filling may provide a long-term nidus for subsequent infection.

\footnotetext{
Interpretation of data from studies evaluating the bacterial species/ phylotypes present in the canal at the time of filling (postinstrumentation or postmedication samples) or retreatmes (postobturation samples).

If a given taxon is found at the filling stage but not at the time of retreatmen this probably means that it succumbec in the filled root canal.

If a given taxon is found both at the time of filling and at the time of retreatment, this may mean that this taxon can cause a persistent infection.

If a given taxon is not detected in samples taken at the time of filling bu is recovered in retreatment samples. this may mean that this taxon gained entry into the canal after filling and then is involved in a secondary infection.
} 


\section{BIOFILM:}

\section{INTRODUCTION:}

The term 'biofilm' was introduced to describe the condensation of microorganisms occurring on various surfaces in nature, including those involved in endodontic infections.

- A 'biofilm' is defined as a structured community of bacterial cells enclosed in a hydrated polymeric matrix of their own synthesis and attached to a solid surface. It is embedded in a self-made matrix of extracellular polymeric substances (EPS) and is a mode of microbial growth where dynamic communities of interacting sessile cells are irreversibly attached to a solid substratum, as well as to each other.

Biofilm mode of growth is advantageous for microorganisms, as they form three dimensional structured communities with fluid channels for transport of substrate, waste products, and signal molecules.

As for the oral cavity, bacterial biofilms, in the form of supra and sub gingival plaque, are involved in both caries and marginal periodontitis.

\section{DEVELOPMENT OF BIOFILM}

Bacteria can form biofilms on any surface that is bathed in a nutrient-containing fluid. The three major components involved in biofilm formation are bacterial cells, a solid surface, and a fluid medium. Development of biofilm is influenced by the physicochemical properties of the components involved in the biofilm.

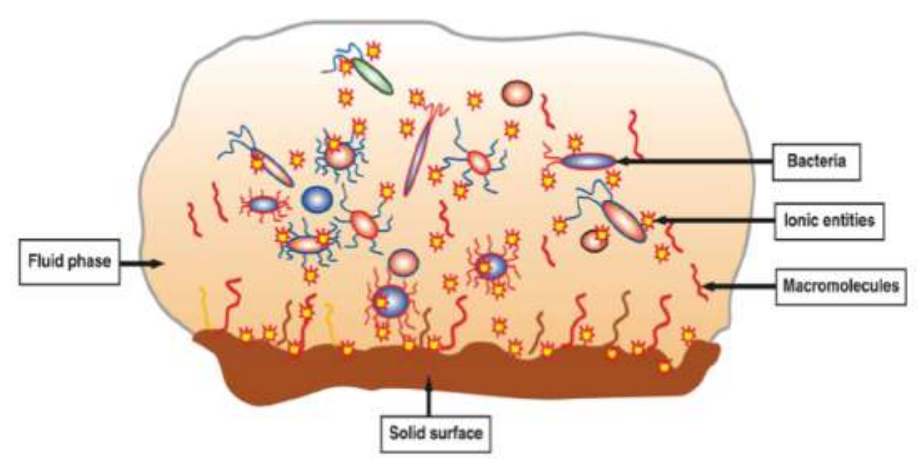

\section{STEPS INVOLVED IN FORMATION OF A BIOFILM:}

The first step involved in the development of biofilm is the adsorption of inorganic and organic molecules to the solid surface creating what is termed a conditioning layer (stage 1). During dental plaque formation, the tooth surface is conditioned by the saliva pellicle.

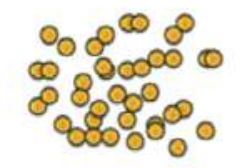

Planktonic cells

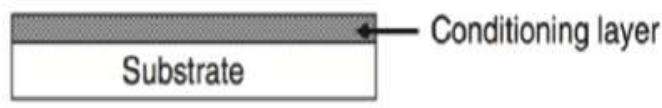

(1) STAGE 1: FORMATION OF CONDITIONING LAYER 
Once the conditioning layer is formed, the next step in biofilm formation is the adhesion of microbial cells to this layer .

Amongst the pioneer organisms, the oralis group of streptococci is the major population to form a bacterial monolayer on the salivary pellicle coated tooth surface.

There are many factors that affect bacterial attachment to a solid substrate. These factors include $\mathrm{pH}$, temperature, surface energy of the substrate, flow rate of the fluid passing over the surface, nutrient availability, length of time the bacteria is in contact with the surface, bacterial growth

Initially, the bonds between the bacteria and the substrate may not be strong. However, with time these bonds gain in strength, making the bacteria-substrate attachment irreversible

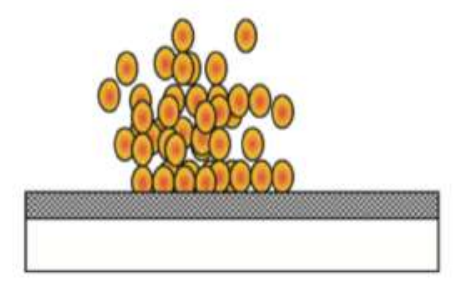

(2) STAGE 2: PLANKTONIC BACTERIAL CELL ATTACHMENT

Finally, a specific bacterial adhesion with a substrate is produced via polysaccharide adhesin or ligand formation (Phase 3: specific microbial- substrate adherence phase). In this phase, adhesin or ligand on the bacterial cell surface will bind to receptors on the substrate. Specific bacterial adhesion is less affected by many environmental factors such as electrolyte, $\mathrm{pH}$, or temperature.
The adhesive potential of microorganisms is considered to be a vital ecologic and pathogenic determinant in the development of biofilms.

The lateral and vertical growth of indwellers gives rise to micro colonies similar to towers. A mature biofilm will be a metabolically active community of microorganisms where individuals share duties and benefits.

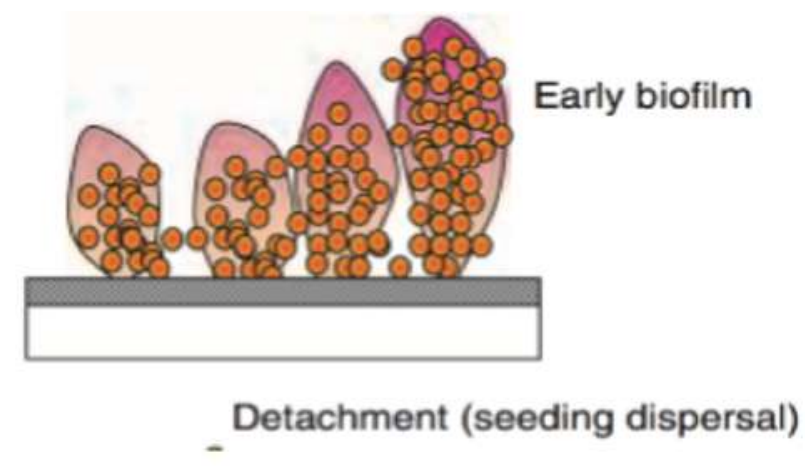

For instance, some microorganisms help in adhering to the solid support, while some others create bridges between different species, which otherwise would not have happened.

Two types of microbial interactions occur at the cellular level during the formation of biofilm. One is the process of recognition between a suspended cell and a cell already attached to substratum. This type of interaction is termed co-adhesion. In the second type of interaction, genetically distinct cells in suspension recognize each other and clump together. This type of interaction is called coaggregation. 


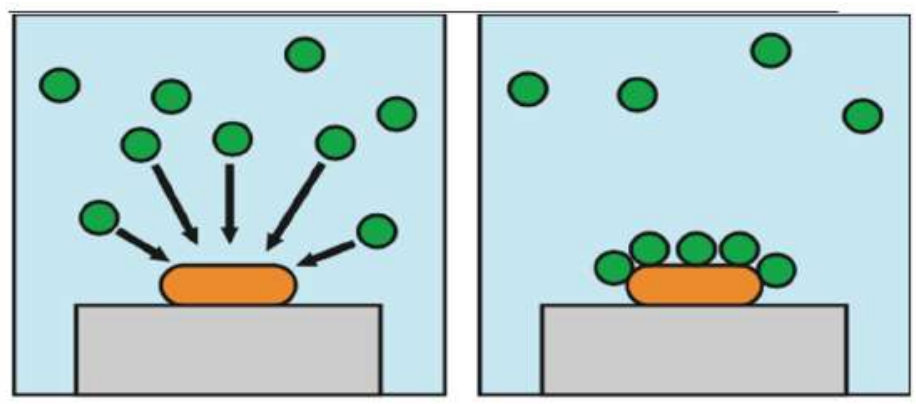

Co-adhesion

In the second type of interaction, genetically distinct cells in suspension recognize each other and clump together. This type of interaction is called coaggregation.

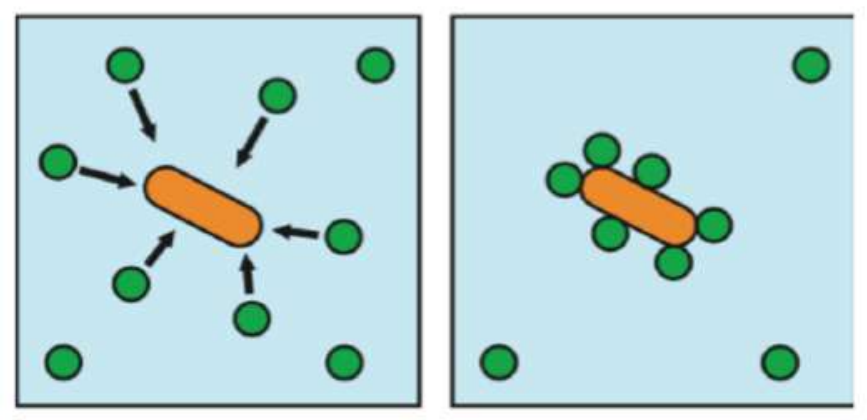

Co-aggregation

\section{RESISTANCE OF MICROBES IN BIOFILM TO ANTIMICROBIALS}

The nature of biofilm structure and physiological characteristics of the resident microorganisms offer an inherent resistance to antimicrobial agents, such as antibiotics, disinfectants, or germicides. The mechanisms responsible for the resistance to antimicrobial agents may include the following:

- resistance associated with the extracellular polymeric matrix

- resistance associated with growth rate and nutrient availability

- resistance associated with the adoption of resistance phenotype

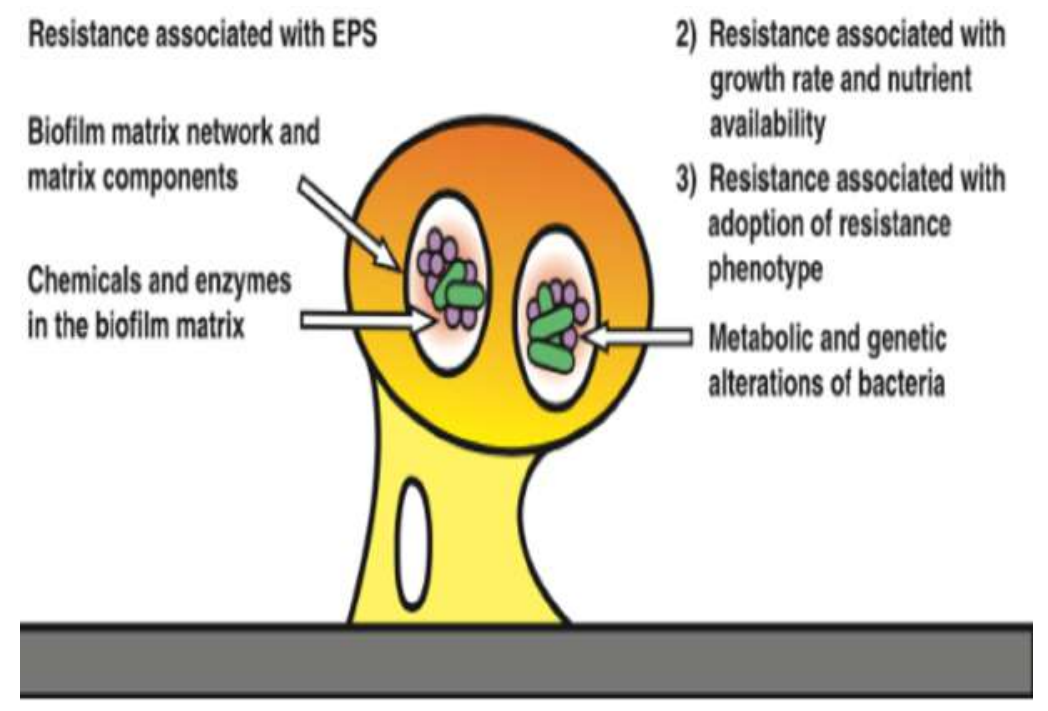


Schematic diagrams of the hypothesized mechanisms of antimicrobial resistance in biofilm bacteria are shown below.
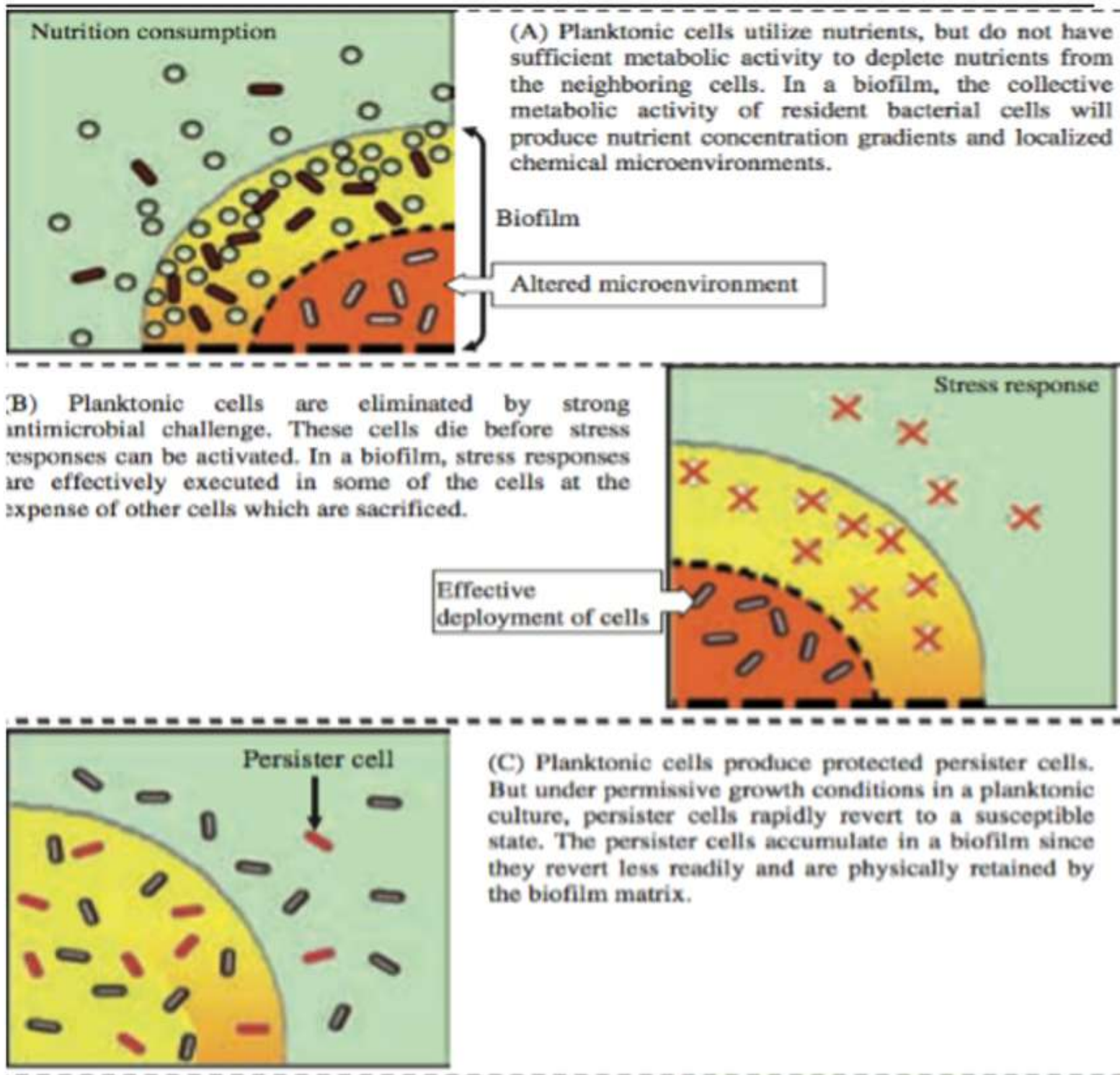

(C) Planktonic cells produce protected persister cells. But under permissive growth conditions in a planktonic culture, persister cells rapidly revert to a susceptible state. The persister cells accumulate in a biofilm since they revert less readily and are physically retained by the biofilm matrix.

D) Planktonic cells neutralize the antimicrobial agent. The capacity of single cell, however, is insufficient to reutralize the antimicrobial concentration in the seighborhood of the cell. In a biofilm, the collective seutralizing power of groups of cells leads to slow or ncomplete penetration of the antimicrobial into the siofilm. 


\section{A. RESISTANCE ASSOCIATED WITH THE EXTRACELLULAR POLYMERI C MATRIX}

Inactivation of antimicrobials by the EPS is said to be an important cause for the observed antimicrobial resistance in biofilm bacteria. EPS, which forms the biofilm matrix, has the potential to modify the response of the biofilm bacteria to antimicrobial treatments through its action as a diffusion barrier and reaction sink (neutralizer). The latter function is enhanced by the retention of extracellular products and enzymes.

It has been suggested that regulation of EPS under the control of signal substances such as $\mathrm{N}$-acyl hemoserine lactone (HSL) is responsible for the early transcriptional events associated with biofilm formation. Such regulators are responsive to increase in cell density beyond critical threshold values and may be general regulators of biofilm specific physiology.

Antibiotics such as aminoglycosides, which are hydrophilic and positively charged molecules, are retarded by the biofilm matrix for the above reason.

Inactivation of antibiotics by the modified enzymes produced by the bacteria in a biofilm state has also been reported. High concentration of enzymes released by bacteria, for example, extracellular enzymes such as blactamase, can inactivate lactam antibiotics. In addition, the biofilm may also retain drug inactivating enzymes within the glycocalyx, which in turn will amplify its barrier properties. The sequestration of $b$ lactamase enzymes or formaldehydelyase and dehydrogenase would cause the degradation of b-lactam antibiotics and formaldehyde, respectively. Thus, the b-lactam resistance of P. aeruginosa biofilms has been associated to b-lactamase retention in the biofilm matrix.

It is suggested that the synergy between bacterial species may also hinder the action of antimicrobials. For instance, E. faecalis can inactivate metronidazole, thereby protecting B. fragilis found in a multispecies biofilm. In another example, Klebsiellaaerogenes, which produce only limited EPS matrix, are protected from antimicrobial agents by other members of the polymicrobial biofilm community that are capable of producing EPS.

\section{B. RESISTANCE ASSOCIATED WITH GROWTH RATE AND NUTRIENT}

\section{AVAILABILITY}

Mature biofilm is composed of multiple layers of bacteria embedded in EPS matrix. The localized high cell density within a biofilm exposes the deep-lying cells to less nutrients and redox potential that are substantially altered from those experienced by the cells on the surface or grown as planktonic cells.

It is established that susceptibility toward most antimicrobial agents varies as a direct function of growth rate, and much of the resistance associated with biofilm bacteria might be associated with slow growing, starved community members.

It is also observed that the resistance to antimicrobial agent's increases in thicker biofilms due to limited oxygen. Because nutrient and gaseous gradients will increase in extent as biofilm thickens and matures, growth rate effect on antimicrobial resistance is particularly marked in aged biofilm.

\section{RSISTANCE ASSOCIATED WITH THE ADOPTION OF RESISTANCE PHENOTYPE}

Long-term survival of biofilm communities results in the adoption or clonal expansion of a more resistant phenotype. Bacteria can sense the proximity of a surface, up-regulate production of EPS, and rapidly alter their susceptibility toward antibiotics and biocides afterbinding (attachment-specific resistance phenotype). Nutrient limitation results in diminished bacterial growth rate, increased expression of stress response genes, shock proteins, and activation of multi-drug efflux pump. The above factors can enhance the 
antibiotic resistance of bacteria in a bio- film. Also,sub-lethal concentration of antibiotics and biocides may act as

inducers/transcriptional activators of more tolerant phenotypes such as those expressing multi-drug resistance operon and efflux pumps.

\section{BIOFILMS IN ENDODONTIC INFECTIONS}

- Biofilm formation in root canals is probably initiated sometime after the first invasion of the pulp chamber by planktonic oral microorganisms after some tissue breakdown, as hypothesized by Svensäter and Bergenholtz.

Endodontic microbiota transition is more conspicuous with the progression of infection. Nutritional and environmental status within the root canal changes as infection progresses. It creates more anaerobic environment and depletion of nutrition which offer a tough ecological niche for the surviving microorganisms. The anatomical and geometrical complexities (e.g. delta and isthmus) in the root canal systems shelter the adhering bacteria from cleaning and shaping procedures

- Endodontic bacterial biofilms are classified as:

- Intracanal biofilms

- Extraradicular biofilms

- Periapical biofilms

- Biomaterial-centered infections.

\section{Intracanal microbial biofilms}

Intracanal biofilms are microbial biofilms formed on the root canal dentin of the infected tooth. Major bulk of the organisms existedas loose collections of filaments, spirochetes, cocci, and rods. Apart from these, bacterial condensations were seen as a palisade structure similar to dental plaque seen on tooth surface.

\section{Extraradicular biofilm}

Extraradicular biofilms formed on the root surface adjacent to the root apex of endodontically infected teeth are root surface biofilms.

\section{Periapical biofilm}

Periapical microbial biofilms in the periapical region of endodontically infected teeth are isolated biofilms which can

be seen even in the absence of root canal infections.

\section{Foreign body-centered biofilm}

Foreign body-centered biofilm is found when bacteria adhere to an artificial biomaterial surface and form biofilm structures. It is also known as biomaterial centered infection. It is a major complication associated with prosthesis and also in implant-supported prosthesis.

- E. faecalis, Str. sanguis, Streptococcus intermedius, Streptococcus pyogenes, Staphylococcus aureus form biofilm on GP points.

- F. nucleatum, Propionibacterium acnes, Po. gingivalis, and Pr. intermedia do not form biofilm on Gutta-Percha(GP) points.

\section{ROLE OF E. FAECALIS IN BIOFILM}

Studies have established the ability of E. faecalis to resist starvation and develop biofilms under different environmental and nutrient conditions (aerobic, anaerobic, nutrient-rich, and nutrient-deprived conditions).

E. faecalis under nutrient rich environment produces typical biofilm structures withcharacteristic surface aggregates of bacterial cells and water channels.

\section{THE DEVELOPMENT OF E. FAECALIS BIOFILM ON THE ROOT CANAL DENTIN INVOLVES THREE STAGES AS FOLLOWS:}

Stage 1: Microcolonies are formed as E. faecalis cells adhere on the root canal dentin surface

Stage 2: Bacterial-mediated dissolution of the mineral fraction from the dentin substrate leads to localized increase in the calcium and phosphate ions causing mineralization (or calcification) of the E. faecalis biofilm

Stage 3: Due to this interaction of bacteria and their metabolic products on dentin, E. faecalis biofilm is mineralized. 


\section{VIRULENCE FACTORS}

Many of the microorganisms found in endodontic infections have also been identified as commensals in the oral cavity that have gained entry into the pulp tissue of the root canal typically via the caries process. The transition from oral "commensal" to root canal "pathogen"' may reflect an innate ability to switch on genes that encode "virulence", factors enabling survival and propagation in a different environment.

\section{A) Lipopolysaccharide (LPS)}

One of the first virulence factors to be identified in endodontic infections is LPS, also known as endotoxin.

Historically, the term "endotoxin' was used based on the understanding that portions of Gram- negative bacteria caused toxicity, as opposed to "exotoxins" that were In Gramnegative bacteria, the outer membrane is constructed of a lipid bilayer, separated from the inner cytoplasmic membrane by PG with the LPS molecule embedded in the outer membrane. The lipid A portion of the molecule serves to anchor LPS in the bacterial cell wall. LPS is an integral part of the cell wall of Gramnegative bacteria regardless of their pathogenicity. When released, LPS has numerous biologic effects, including the mobilization of immunosurveillance mechanisms in the pulp. produced by bacteria and secreted into their environment.

\section{B) Peptidoglycan (PG)}

$\mathrm{PG}$ is the major component of Gram-positive cell walls where it forms a layer which is considerably thicker than in Gram-negative bacteria. PG functions to counteract osmotic pressure of the cytoplasm and provides cell wall strength and shape. It is a cross-linked complex consisting of polysaccharides and peptides that form a homogeneous layer outside the plasma membrane. Specifically, it is composed of interlocking chains of identical PG monomers. Each monomer consists of two joined amino sugars, Nacetyl glucosamine and
N-acetylmuramic acid (NAM), with a pentapeptide attached to the NAM.

\section{C) Lipoteichoic Acid (LTA)}

LTA is a cell wall component of Gram-positive bacteria, composed of echoic acid and lipid. LTA shares with LPS many of its pathogenic properties but is reported to be much less active, on a weight- for-weight basis. The lipid component of LTA may be involved in the binding of Gram-positive bacteria to fibronectin in cell membranes and to eukaryotic cells that include neutrophils and lymphocytes.

\section{D) Fimbriae}

Fimbriae are long, filamentous macromolecules found on the surface of many Gram-negative bacteria. The thin hair- like projections are made of protein subunits. They are distinct from flagella, which are longer and involved in cell motility. Fimbriae are involved in attachment to surfaces and interactions with other bacteria. Enteric pathogens, for example, E. coli and Salmonella spp, have a diverse array of fimbriae that are involved in bacterial adherence and invasion.

\section{E) Capsules}

An important element in the virulence of pathogenic microorganisms is their ability to evade or counter- act host immune defenses. One strategy used by bacteria and fungi utilizes capsule formation to inhibit complement activation and resist ingestion by phagocytes. A capsule is a well-organized layer outside the cell walls of the bacteria generally composed of polysaccharides and other materials. Capsules serve to facilitate protection of the bacterial cell against desiccation, phagocytosis, bacterial viruses, and hydrophobic toxic materials such as detergents.

\section{F) Extracellular Vesicles}

Extracellular vesicles are produced by Gramnegative bacteria and allow the release of their products into the extracellular environment. They develop from evagination of the outer 
membrane and have a similar trilaminar structure as their parent cell.

MICROBES ASSOCIATED WITH ROOT CANAL FAILURE

\section{BACTERIAL PERSISTENCE AS A RISK FACTOR FOR POSTTREATMENT DISEASE}

Most intracanal bacteria are sensitive to standard treatment procedures. Nevertheless, some bacteria may survive treatment procedures, and their presence at the time of filling as detected by various culture techniques that has been recognized as a risk factor for posttreatment apical periodontitis. In cases of treatment failure, longitudinal studies evaluating bacteria at the filling stage and further at the time of retreatment have the potential to determine bacterial species/phylotypes as risk factors for posttreatment disease. Studies have shown that Enterococcus faecalis is the most commonly found species in root canal-treated teeth exhibiting emergent/persistent disease. This might be interpreted as this species being a risk factor for persistent disease. However, E. faecalis has been rarely found in primary infections and not so frequent, if ever found, as a persisters at the time of filling except in cases treated in multiple visits and/or in teeth left open for drainage.

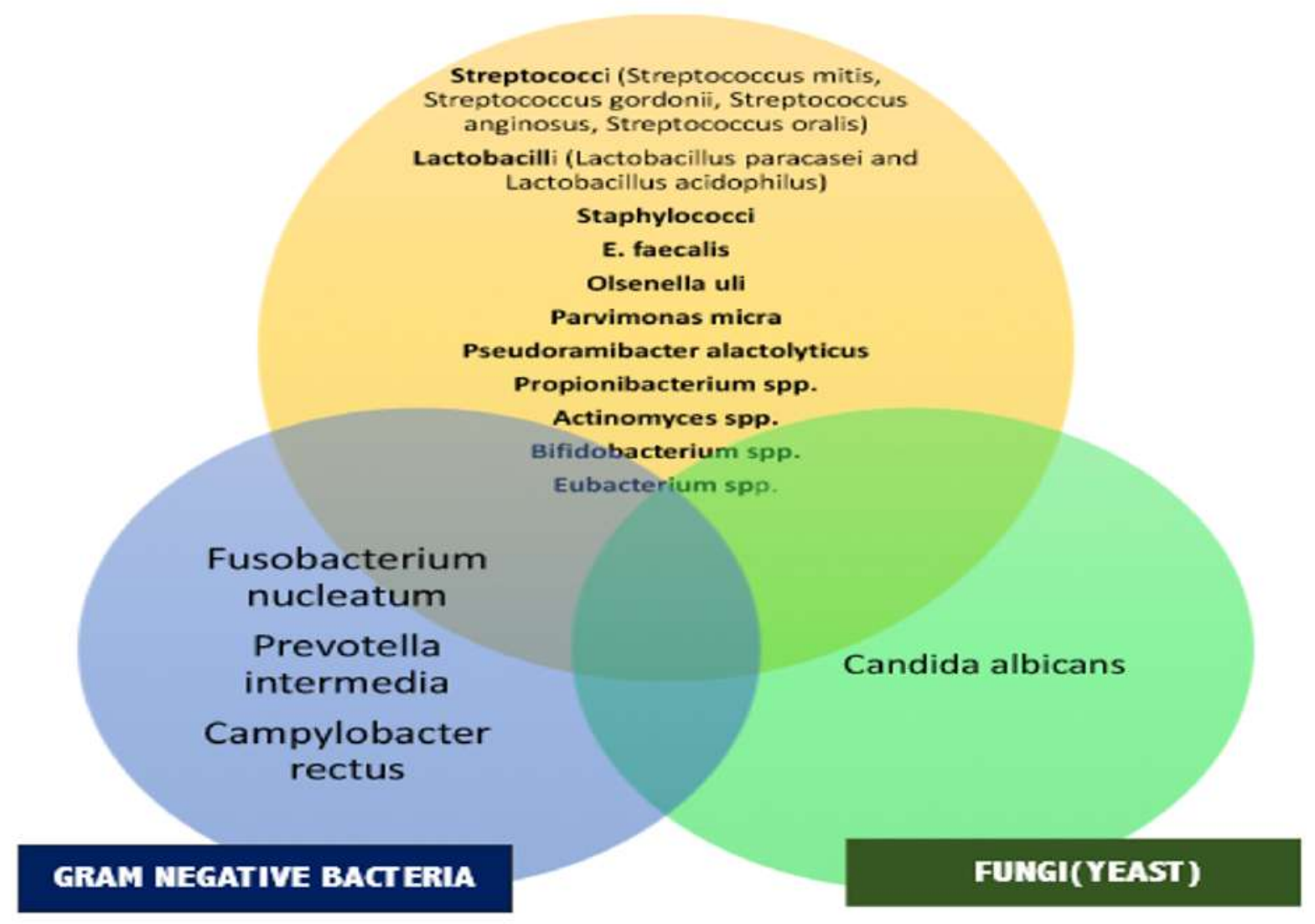

\section{GRAM POSITIVE BACTERIA}

Theoretically, taxa detected at the filling stage but not at the time of retreatment may not be able to endure the conditions within obturated root canals. Likewise, taxa found only at the time of retreatment but not at the time of filling may represent secondary infections that 
developed by lack of a bacteria-tight coronal seal. Still following this train of thought, taxa found at both the time of filling and during retreatment of failed cases may be involved in persistent infections.

\section{A) GRAM POSITIVE BACTERIA: 1. ENTEROCOCCI:}

Enterococcus is a genus of Gram-positive facultative anaerobic cocci bacteria that until 1984were classified as Group D streptococci. Enterococcal cells are ovoid and occur singly or in pairs or short chains and can grow at temperatures ranging from 10 to $45 \mathrm{C}$. They catabolize a variety of energy sources including carbohydrates, glycerol, lactate, malate, citrate, arginine, agmatine, and many keto acids.Enterococci survive very harsh environments including extreme alkaline $\mathrm{pH}$ and salt concentrations. They resist bile salts, detergents, heavy metals, ethanol, azide, and desiccation.

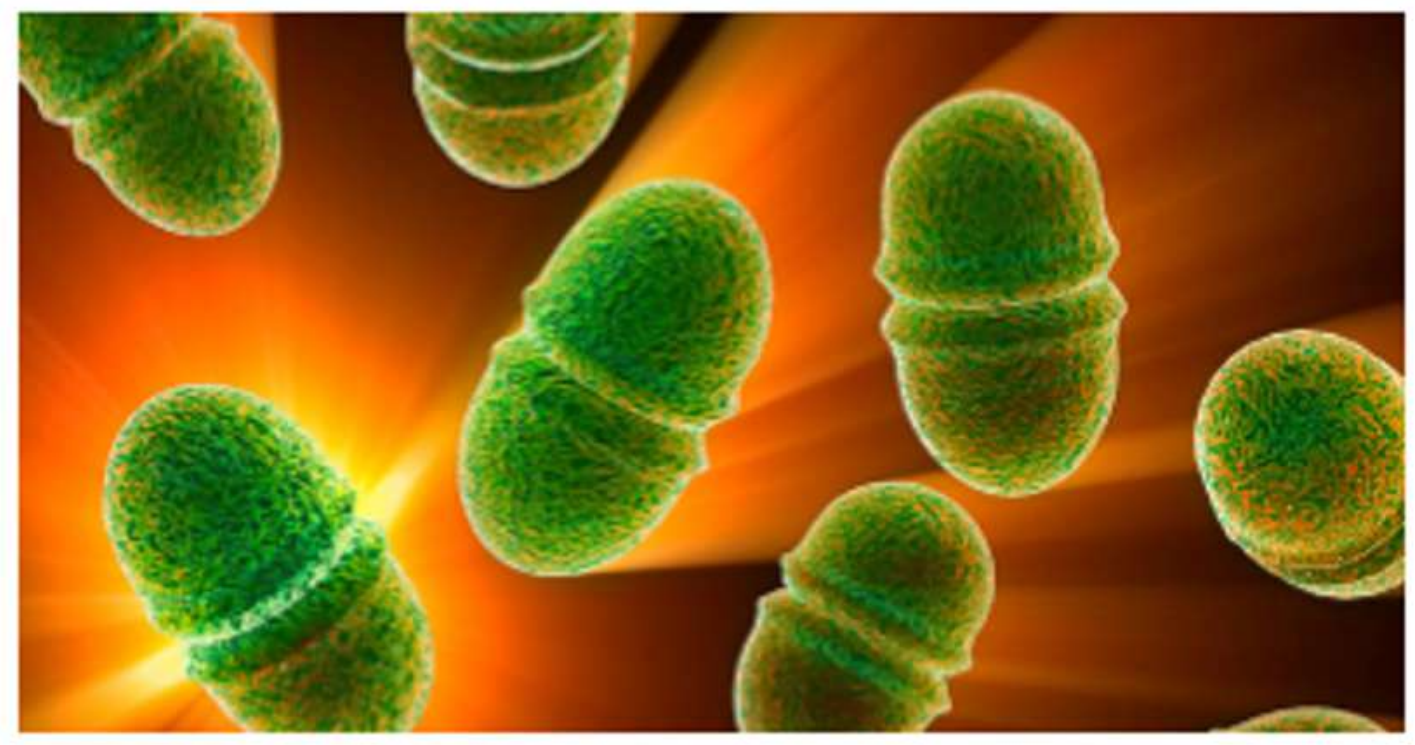

E. faecalis and E. faecium are the most common Enterococcal species found in humans. After coagulase-negative staphylococci, E. faecalis is the most common bloodstream nosocomial pathogen and can also cause urinary tract infections, abdominalpelvic infections, infective endocarditis, and prosthetic joint infections, among other infections.

Multiple antibiotic resistance by E. faecalis is a major factor in its prominence in nosocomial infections. E. faecalis exhibits an intrinsic resistance to many antibiotics, for example, blactams antibiotics, most aminoglycosides, and clindamycin,136 and can commonly harbor multiple antibiotic resistance determinants carried on transferable plasmids.

\section{PREVALENCE OF ENTEROCOCCI IN PREVIOUSLY ROOT- FILLED TEETH}

Both culture and molecular-based studies have demonstrated that $\mathrm{E}$. faecalis could also be recovered from root canals with primary infections. Strains have been recovered from approximately one-third of root canals of failed endodontically treated teeth in culture studies and over $70 \%$ using PCR-based methods of detection.

Using sampling and culture techniques based on the "gold standard" method of Moller, E.faecalis was recovered from root canal samples in $30 \%$ of culture-positive cases in Sweden and the United States. In contrast, investigations using $16 \mathrm{~S}$ rDNA based endpoint PCR reported that E. faecalis was detected in 
$77 \%$ of samples from 22 failed endodontically treated teeth undergoing retreatment and in $67 \%$ of 30 cases of persistent endodontic infections associated with root-filled teeth in Brazil.

\section{POTENTIAL ROLE OF E. FAECALIS IN UNSUCCESSFUL ROOT CANAL TREATMENT}

The pathogenicity of enterococci in endocarditis and peritonitis has long been established in animal models. In contrast, despite their frequent recovery, whether E. faecalis plays a significant role in the pathogenesis of human root canal infections remains unclear.

In studies concerning the survival of selected bacterial strains inoculated into monkey root canals, after 8-12 months E. faecalis was the only species to be re-isolated from all 24 root canals as well as produce radiographic evidence of apical periodontitis in all cases. It has been hypothesized that in periapical infections that involve E. faecalis, tissue damage may be predominantly caused by the host response to the bacteria rather than direct damage from bacterial products. Thus, the repeated recovery of enterococci from root canal samples may instead represent an ability to survive in the root canal.

Studies investigating its occurrence in rootfilled teeth with periradicular lesions have demonstrated a prevalence ranging from 24 to $77 \%$. The wide range of $\mathrm{E}$. faecalis prevalence among studies may be attributed to different identification techniques, geographic differences, or sample size.

polymerase chain reaction (PCR) is currently a more predictable method for detection of $\mathrm{E}$. faecalis. This method proves to be faster, more sensitive, and more accurate than other culturing methods. It has enabled researchers to detect bacteria that were difficult, and in some cases impossible, to detect When compared to detection of E. faecalis by culturing $(24-70 \%)$, E. faecalis has been found at consistently higher percentages $(67-77 \%)$ when a PCR detection method is used.

\section{SURVIVAL AND VIRULENCE FACTORS}

E. faecalis possesses certain virulence factors including lytic enzymes, cytolysin, aggregationsubstance, pheromones, and lipoteichoic acid.It has been suggested that enterococci may be selected in root canals undergoing standard endodontic treatment because of low sensitivity to antimicrobial agents, including the ability to resist the high $\mathrm{pH}$ of antimicrobial agents commonly used, such as calcium hydroxide paste For example, E. faecalis transcripts of ftsZ, a gene involved in cell division, was observed to increase.

Another mechanism by which E. faecalis colonization of treated root canals with $\mathrm{E}$. faecalis might occur is by the formation of coaggregate with other species, for example, $F$. nucleatum. Coaggregation interactions occurring in bio- films may provide an effective means by which E.faecalis remain in the root canal ease by 37 -fold after 5 days incubation at $\mathrm{pH} 10$ at $37 \mathrm{C}$. But at a $\mathrm{pH}$ of 11.5 or greater, E. faecalis is unable to survive.

Virulence factors with the potential to promote adaptation and survival in different environments have been identified in enterococci recovered from infected root canals as well as other sources.

These include enterococcus surface protein (Esp.), collagen- binding protein (Ace), and, as well as factors that enable secretion of proteases (e.g. gelatinase) and toxins (e.g., cytolysin).Production of serine protease and Ace by E. faecalis have been shown to contribute to the ability to bind to dentin, and AS can promote resistance to killing by human neutrophils.

Calcium hydroxide, a commonly used intracanal medicament, has been shown to be 
ineffective at killing E. faecalis on its own, especially when a high $\mathrm{pH}$ is not maintained. The following reasons have been proposed to explain why E. faecalis is able to survive intracanal treatment with calcium hydroxide:

(a) E. faecalis passively maintains $\mathrm{pH}$ homeostasis. This occurs as a result of ions penetrating the cell membrane as well as the cytoplasm's buffering capacity.

(b) E. faecalis has a proton pump that provides an additional means of maintaining $\mathrm{pH}$ homeostasis. This is accomplished by "pumping" protons into the cell to lower the internal $\mathrm{pH}$.

(c) At a $\mathrm{pH}$ of 11.5 or greater, E. faecalis is unable to survive. However, as a result of the buffering capacity of dentin, it is very unlikely that a $\mathrm{pH}$ of 11.5 can be maintained in the dentinal tubules with current calcium hydroxide utilization techniques.

\section{STREPTOCOCCUS}

Streptococcus is a genus of Gram-positive, sporogenous, facultative anaerobic, catalasenegative cocci or coccoid bacteria. They are non-motile and typically approximately $1 \mathrm{~mm}$ in diameter, occurring in pairs or chains. Several species can form capsules. Streptococcus forms part of the normal commensal microbiota of the mouth, skin, intestine, and upper respiratory tract of humans.

Traditional classification of Streptococcus species relied on their phenotypic properties, with four species groups designated A, B, C, and D. Many group D streptococci have been reclassified as Enterococcus.
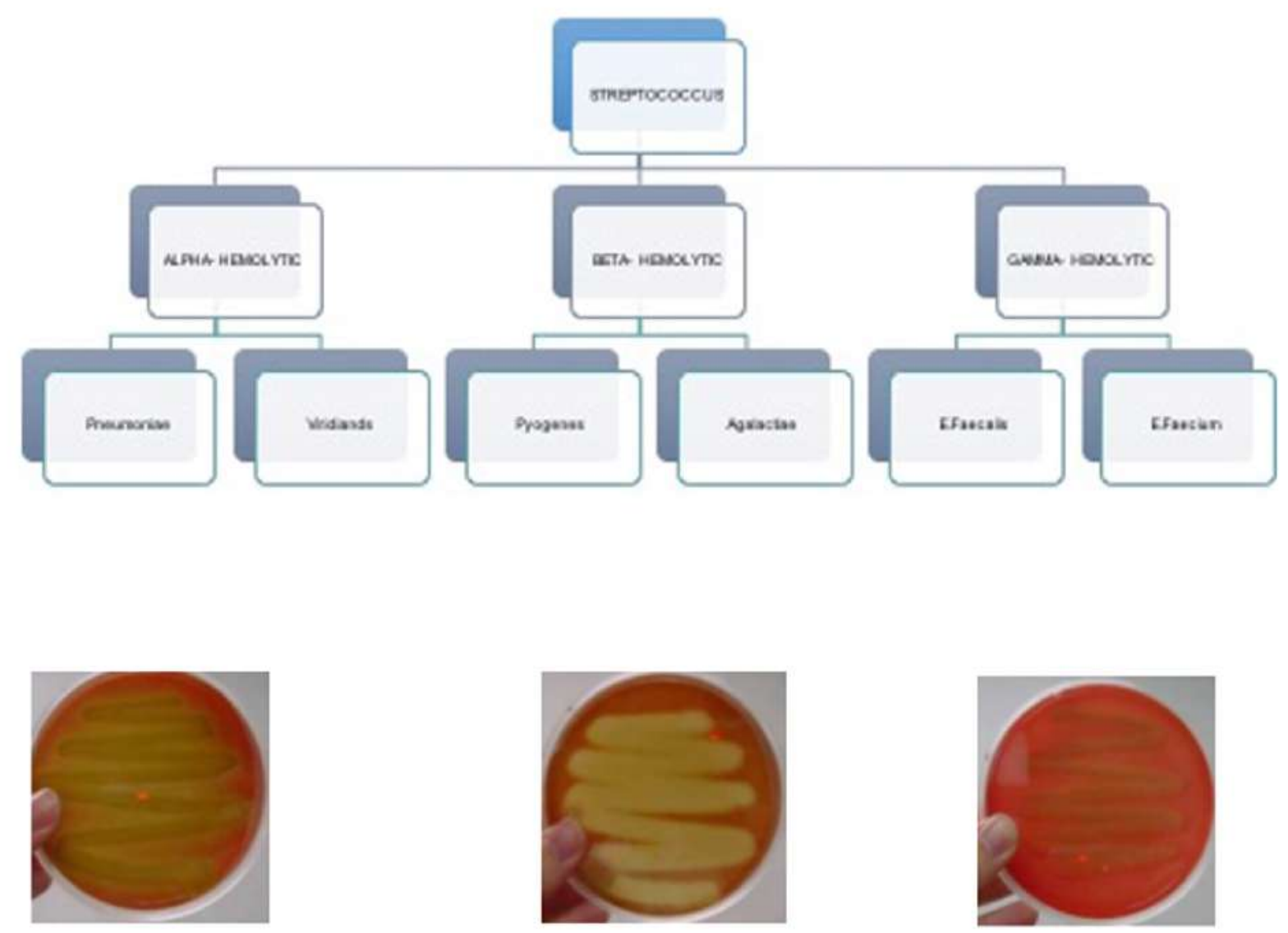
"Alpha" hemolysis reduces iron in hemoglobin, resulting in a greenish color on blood agar. Alpha hemolytic streptococci are commonly referred to as "viridians" streptococci and area among the major causative microorganisms of infective endocarditis.34 S. mutans, an important species in dental caries, is an example of alpha hemolytic oral streptococci.

"Beta" hemolysis results in complete rupture of red blood cells and gives distinct, clear areas around bacterial colonies on blood agar. Beta hemolytic streptococci, for example, S. pyogenes ,have been implicated in bacteremia and a range of streptococcal infections, including pharyngitis, rheumatic fever, and acute glomerulonephritis.

\section{PREVALENCE OF STREPTOCOCCI IN PREVIOUSLY ROOT-FILLED TEETH}

Culture studies have shown that in teeth with clinical and radiographical signs of apical periodontitis, streptococci (and lactobacilli) appear to survive following root canal treatment although less frequently than enterococci. In teeth with apical periodontitis receiving endodontic treatment, the most frequently isolated streptococci were $\mathrm{S}$. gordonii, S. anginosus, and S. oralis. In more than half of the culture positive samples, S. gordonii and $\mathrm{S}$. oralis still predominated in subsequent samples. Streptococcus intermedius, S. anginosus, S. oralis, and S. gordonii recovered from root canals were strong producers of extracellular proteins suggesting that these species may play a significant role in post-treatment apical periodontitis. Typically, streptococci recovered from periapical lesions are only rarely resistant to antibiotics commonly used for the treatment of endodontic infections

\section{POTENTIAL ROLE OF STREPTOCOCCI IN UNSUCCESSFUL ROOT CANAL}

Treatment in root-filled teeth with persisting periapical lesions, significant positive associations were observed between the presence of a sinus tract and Streptococcus spp and between coronally unsealed teeth and Streptococcus spp. In endodontically treated teeth associated with asymptomatic periapical lesions in patients in Hong Kong, streptococci, as well as coagulase-negative staphylococci and $\mathrm{P}$. aeruginosa were most frequently isolated.

The effect of streptococci on periapical tissue in humans is not well understood. Using FISH colonies with Streptococcus spp were seen in some periapical lesions of asymptomatic rootfilled teeth, suggesting a positive association. However, in monkeys, 8-12 months after being introduced into root canals, $85 \%$ of teeth from which Streptococcus milleri was recovered had radiographic evidence of apical periodontitis, although the contribution of anaerobic bacteria to the infection could not be eliminated.

The virulence factors of $\mathrm{S}$. mutans are diverse and are often proteins associated with the cell wall. More specifically, glucan-binding proteins participate in plaque cohesion and can play a role in the modulation of virulence.

The cell walls of Gram-positive bacteria contain PG and LTA that are released upon lysis of the cell. PG and LTA can bind to cell surface receptors and induce the release of proinflammatory cytokines. LTAs are present on the cell surface of most oral streptococci and are important virulence factors, sharing many pathogenic properties with the LPS of Gramnegative bacteria. Lysis of the bacterial cell induced by lysozyme, cationic peptides from leukocytes, or beta- lactam antibiotics results in release of LTA. 
Streptococci also have a large range of cell surface adhesins that facilitate binding to various substrates including other bacterial cells, epithelial cells, and dentin. S. gordonii amylase-binding protein A functions as an adhesin to amylase-coated HAP and in human saliva-supported biofilm formation.

\section{ACTINOMYCES}

Actinomyces species are non-spore-forming Gram- positive bacteria occurring as rods, branched rods or filaments, or as rudimentary mycelia. All species can grow anaerobically. Many Actinomyces species are commensals in the oral cavity but can become opportunistic pathogens in humans and other mammals. Occasionally, they cause actinomycosis, a disease characterized by the formation of abscesses in the mouth, lungs, or the gastrointestinal tract.

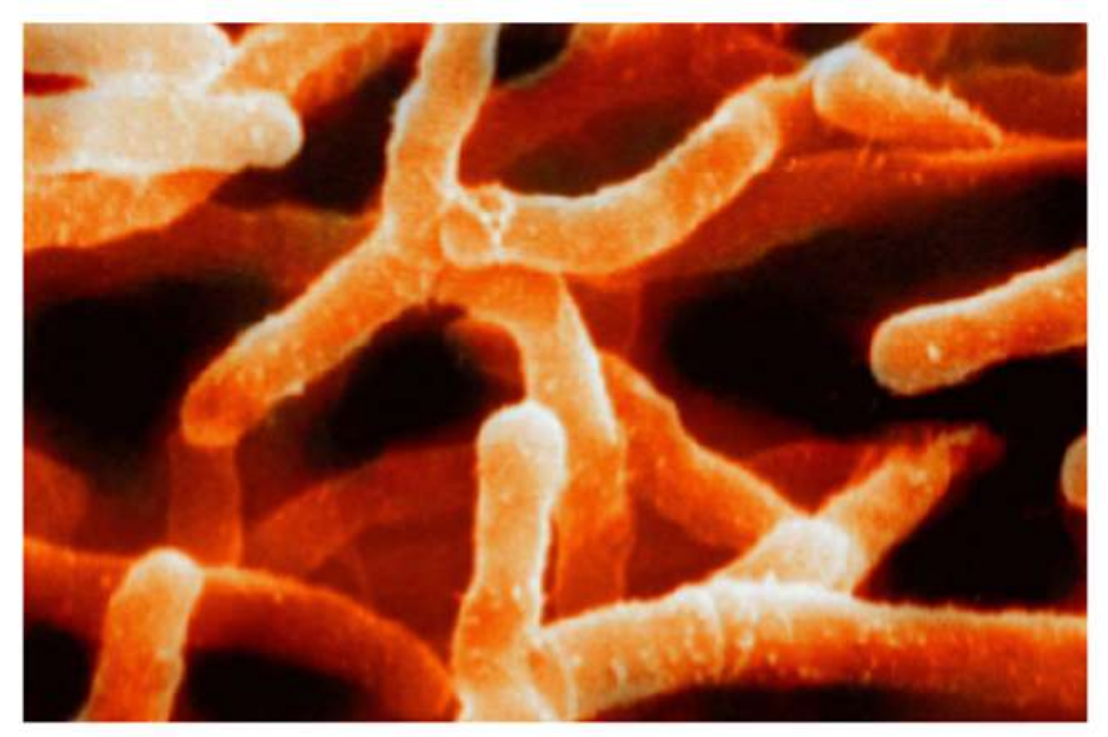

Happonen et al.reported that A. israelii was involved in osteoradionecrosis of the jaws in 1983. Recently, Actinomyces has been described as an important pathogen in infected osteoradionecrosis following radiation therapy for head and neck cancer.

Actinomyces species have been implicated in root caries. Species recovered from active root caries include A. israelii, A. naeslundii, Actinomyces gerencseriae, Actinomyces odontolyticus, and Actinomyces georgiae with more than one species isolated from individual lesions. In germ-free rats, A. israelii was shown to cause root surface caries and invasion of pulp tissue. In patients with periodontally affected non-vital teeth, the periodontal pocket may provide a source of Actinomyces.

\section{Prevalence of Actinomyces in Previously Root-Filled teeth}

In primary root canal infections, reports of recovery of Actinomyces are not uncommon. Actinomyces was predominant in the apical 5 $\mathrm{mm}$ of root canals of extracted teeth with carious pulpal exposures and periapical lesions contiguous with the root apex in culture studies.

Actinomyces species also have been implicated in secondary root canal infections nonresponsive to conventional treatment. The presence of Actinomyces in a periapical cyst has also been reported. Strains of the species Actinomyces radicidentis were first found in the root canal and periapical abscesses from two patients with persisting infections following endodontic treatment. Since then, 
there have been reports of recovery of A. radicidentis from previously filled root canals in endodontic patients who had persistent signs and symptoms after conventional root canal and also in two primary infection cases.

\section{GRAM NEGATIVE BACTERIA}

\section{PROPIONIBACTERIUM}

Propionibacterium species are slow-growing, non-sporulating, Gram-positive anaerobic rods with propionic acid, an end product of fermentation. While Propionibacterium species are normal inhabitants of the skin and usually nonpathogenic, they are also common contaminants of blood and body fluid cultures. The human cutaneous propionibacteria include P. acnes, Propionibacterium avidum, Propionibacterium granulosum, Propionibacterium innocuum, and P. propionicum (also called Propionibacterium propionicus, and formerly Arachnia propionica).

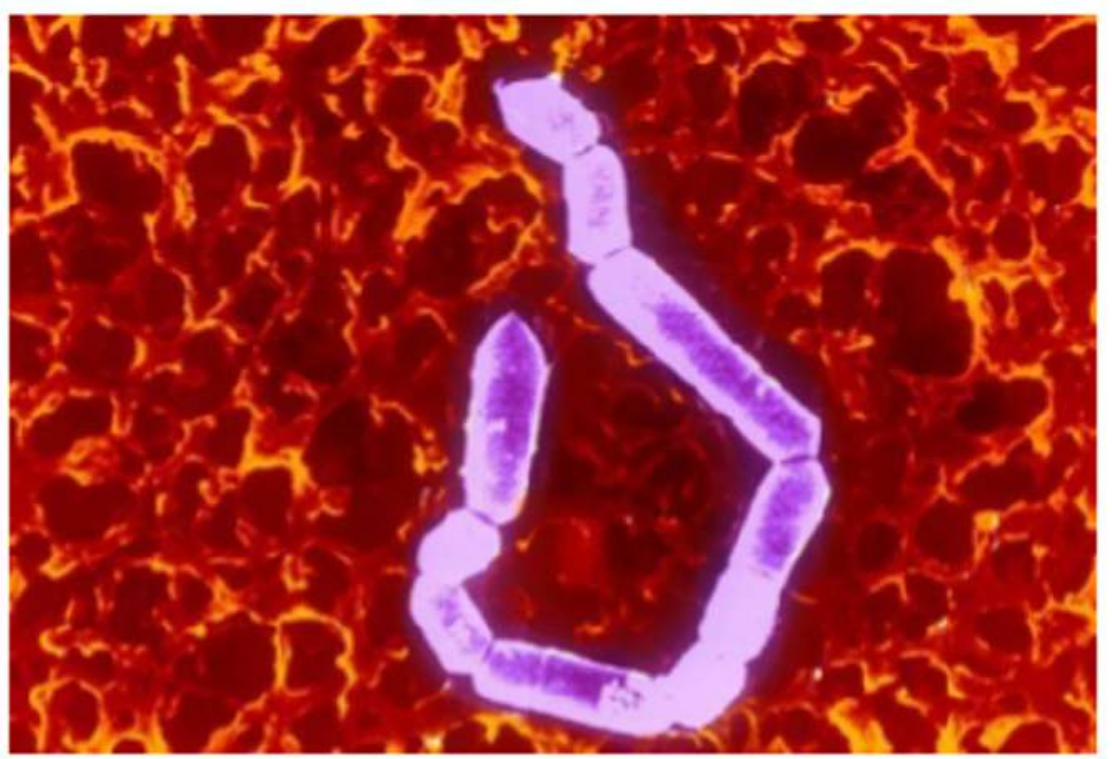

They can be opportunistic pathogens, causing a diverse collection of infections that includes acnes vulgaris, brain abscesses, central nervous system infections, and infective endocarditis. P. propionicum is frequently associated with infections of the lacrimal apparatus and has been implicated as a less common causative agent of a disease process similar to actinomycosis. P. propionicum has been cultured from shallow and deep coronal caries and deep layers of infected root canal dentin. Prevalence of Propionibacteria in Previously Root-Filled Teeth.

$\begin{array}{lrr}\text { POTENTIAL } & \text { ROLE } & \text { OF } \\ \text { PROPIONIBACTERIA } & \text { IN } \\ \text { UNSUCCESSFUL ROOT } & \text { CANAL } \\ \text { TREATMENT } & & \end{array}$

Although a $\mathrm{P}$. propionicum isolate from a failed root- filled tooth did not survive in connective tissue in guinea pigs, there is some evidence that the species possesses characteristics that might facilitate its survival in conditions found in the treated root canal, including an ability to penetrate into dentinal tubules.

The surface fibrillar layer that forms part of a complex cell wall structure contributes toward resistance to phagocytosis. In addition, Propionibacterium can survive and persist intracellularly in macrophages.

P. acnes was shown to survive for 8 months under anaerobic conditions without subculture in vitro, suggesting that it could also survive in human tissues at low oxidation potentials. 


\section{FUNGI(YEAST)}

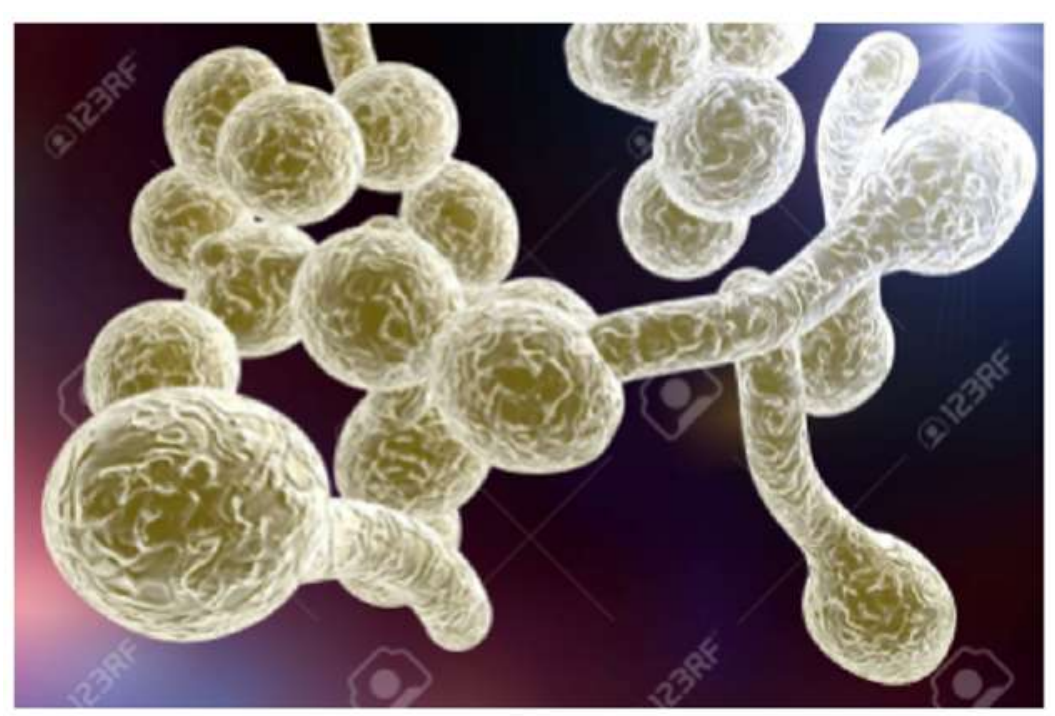

Yeasts are unicellular fungi. The most clinically relevant yeasts belong to the large heterogeneous genus Candida, with members forming part of the commensal microbiota in many parts of the human body. Candida species can also be opportunistic pathogens as they have the ability to colonize and infect nearly all human tissues. They make up $12 \%$ of bacteremias in intensive care units, and are a leading cause of infections in immunocompromised hosts, causing systemic candidiasis in severely immunocompromised patients. C. albicans is the most common oral yeast, with other relevant species being Candida glabrata, Candida krusei, and Candida tropicalis.

Non- C. albicans yeast infections may occur in patients who have received azole-based antifungal therapy.70 C. albicans cells are significantly larger than bacteria and can switch between several different phenotypes in a manner that is heritable and reversible.71 Candida spp reproduce by means of multilateral budding and can form biofilms and tolerate a range of $\mathrm{pH}$ conditions. The cell walls are rigid and contain mannan, glucan, and chitin. Cell surface hydrophobicity and $\mathrm{pH}$ influence the adherence of Candida to host cells.

\section{PREVALENCE OF YEASTS IN PREVIOUSLY ROOT-FILLED TEETH}

While yeasts are occasionally recovered from primary root canal infections, they may be more frequently recovered from root canals of obturated teeth in which treatment has failed. Yeasts may gain access to the root canal during treatment via contamination. The presence of yeasts in root canals was significantly associated with their presence in saliva and with coronally unsealed teeth.

While there appears to be sufficient data to consider yeasts as potential non-bacterial causes of endodontic failures, it is not clear if the prevalence of Candida is different in teeth with primary compared to secondary root canal infections. Culture studies showed that $10 \%$ of primary cases involved the presence of Candida spp, compared to $15 \%$ and $3 \%$ of rootfilled teeth with chronic periodontitis in Lithuania and Sweden, respectively, and 7\% of culture positive samples in 967 samples from persistent endodontic infections in Finland. 


\section{POTENTIAL ROLE OF YEASTS IN UNSUCCESSFUL ROOT CANAL TREATMENT}

In 4 of 10 extracted teeth with necrotic pulps and periapical lesions, heavy infection with yeasts was observed under scanning electron microscopy (SEM), and subsequent SEM studies showed hyphae and budding yeast cells (blastospores) penetrating into dentinal tubules suggesting that C.albicans had an affinity to dentinal structures. Penetration into dentinal tubules by C. albicans was less than E. faecalis in vitro. Thick biofilm formation was associated with the presence of the smear layer, suggesting it provided a suitable substrate for attachment and growth of C. albicans. This was supported by the observation that, following dentin treatment with ethylene diamine tetraacetic acid (EDTA) and $\mathrm{NaOCl}$ to remove smear layer, biofilm formation by C.albicans was hindered.

Clinical strains of C. albicans recovered from infected root canals in samples in Finland revealed genotypic and phenotypic diversity, but were similar to strains from other oral and non-oral sites, suggesting that $\mathrm{C}$. albicans strains from infected root canals do not require unique characteristics to exist in the root canal environment. Yeasts may play an important role in cases of persisting apical periodontitis, although the mechanisms are not clear.

Because fungi is involved mainly in failed cases the spectrum of endodontic medicaments and irrigants should have antifungal effectiveness which may assist in successful management of persistent or secondary endodontic infection caused by fungi.

Sen et al investigated the antifungal properties of $0.12 \%$ chlorhexidine, $1 \% \mathrm{NaOCl}$ and $5 \%$ $\mathrm{NaOCl}$ and found C.Albicans to be more resistant in the presence of smear layer than in its absence.

It was said that EDTA exhibited antifungal properties in 2 particular ways: anticolonization(reducing adhesive properties 0 and antigrowth (decreasing metabolic activity and pathogenicity of C.Albicans by extracting ca ion from cell wall and medium.)In another study Sen et al invested antifungal properties of EDTA and revealed that it had most effective antifungal activity.

Nystatin, ketoconazole and $1.5 \%$ chlorhexidine gluconate solution exhibited the next most effective activity. Waltimo et al studied the susceptibility of common oral candida species to saturated aqueous calcium hydroxide solutions. They observed that all candida species showed either equally high or higher resistance to calcium hydroxide than did E.Faecalis. Due to resistance to contemporary calcium hydroxide formulation renewed interest has been generated regarding the association of calcium hydroxide with antimicrobial substances such as CPMC, Chlorhexidine, iodine or potassium iodide.

Ferguson et al in his study revealed that $\mathrm{NaOCl}$, hydrogen peroxide and chlorhexidine digluconate were effective C.Albicans even when significantly diluted.

IPI used as intra-visit dressing for $10 \mathrm{~min}$ has also shown promise as a endodontic disinfectant.

\section{METHOD OF ERADICATION}

\section{IMPORTANCE OF ASEPSIS}

Since the primary goal of endodontic therapy is the elimination of bacteria from the root canal, an essential requirement during treatment is that it be undertaken in a sterile environment where further contaminating micro-organisms can be reliably excluded from the canal.

The importance of using sterile instruments and an aseptic technique in a disinfected field cannot be over- emphasized, since failure to do so may have a direct bearing on the outcome of treatment. 
Every effort should be made to exclude and eliminate micro-organisms from the operative field and the root canal itself.

The treatment of root canal infections is unique in the sense that it is possible to isolate the area from the rest of the oral cavity by use of rubber dam. Application of the rubber dam is mandatory for endodontic treatment. The rubber dam must properly isolate the tooth from the oral cavity to ensure an aseptic field.

Efficient methods are available for disinfection of the operative field, the tooth and rubber dam.

Once the tooth is isolated from the oral cavity, the tooth surface and adjacent rubber dam should

be cleaned with $30 \%$ hydrogen peroxide, taking care to ensure that the skin and eyes of thepatient and staff are protected. The same area is then carefully disinfected by scrubbing the area with 5\% tincture of iodine, 160 sodium hypochlorite or $2 \%$ chlorhexidine in alcohol. These procedures are simple yet effective and greatly reduce the chances of contaminating the open root canal. This disinfection process will establish a surgical field, allowing a high degree of asepsis.

\section{ANTIMICROBIAL EFFECT OF DEBRIDEMENT}

Preparation of the root canal consists of two main phases:

debridement by manual and mechanical instrumentation

chemical disinfection by irrigation and subsequent antibacterial dressing.

The control of bacteria within the root canal might appear to be straightforward since such a large proportion of the bacterial flora is sensitive to oxygen. However, the penetration of oxygen into the canal during treatment does not seem to have any significant effect on the bacteria. The reason for this is that many of the bacteria are protected in the irregularities and branches of the root canal system and in dentinal tubules. Only a few cells need to survive treatment so that when the canal is closed, the anaerobic milieu will be restored and the bacteria can re-multiply.

Thus, the microbial flora within the root canal must be actively eliminated by a combination of physical debridement and antimicrobial chemical treatment.

Although the most important aspect of root canal instrumentation is undoubtedly the elimination of bacteria and the removal of remnants of pulp tissue and debris, the shaping of the root canal to accommodate the root filling material is also of importance.

A great deal has been written about the preparation of the root canal to achieve a tapering163form since this shape facilitates cleaning of the apical third, preserves the apical foramen from over-instrumentation and facilitates filling of the canal.

To remove the debris from the instrumentation, the root canal is irrigated and the fluid is evacuated with a suction device. Antimicrobial agents have been used in endodontic therapy for more than a century. Saline, various antimicrobial agents and their combinations have been used for irrigation. Most common has been quaternary ammonium compounds (cationic deter- gents), iodophores, and sodium hypochlorite solutions.

The relative effectiveness of these measures has been studied in a series of investigations with advanced bacteriological techniques and the cleansing effect of the mechanical instrumentation has been studied by histology164 and by scanning electron microscope (SEM) analysis of the appearance of the root canal wall before and after instrumentation of the root canal.

\section{ANTIMICROBIAL EFFECT OF INSTRUMENTATION}

Infected root canals can harbor between 102 to more than 109 bacterial cells. Manual 
instrumentation with $6-10 \mathrm{ml}$ of saline per canal can reduce the number of bacteria in infected root canals by 100 to 1000 - fold. However, root canal preparation with hand files and saline irrigation is only moderately effective. Early studies in which no antiseptic irrigants were used reported that 20 to 30 per cent of the root canals that were infected at the beginning of treatment yielded negative cultures at the end of the first appointment Using advanced bacteriological techniques, it has been shown that the number of bacteria can be significantly reduced, but not to an extent that negative cultures can be reliably obtained at the end of the first appointment. This underlies the importance of supporting the mechanical cleaning of canals with antimicrobial irrigation.

SEM studies of canals that have been manually instrumented with saline irrigation show that loose debris can be eliminated from the upper and middle thirds of the root canal. Filing with endodontic instruments translocate and burnishes the superficial components (organic and inorganic) of the circumpulpal dentine and creates an amorphous smear layer on the canal walls. This layer is not affected by irrigation with saline.

\section{ANTIMICROBIAL EFFICACY OF ROTARY NITI INSTRUMENTATION}

Engine-driven instruments make canal preparation faster and less tedious than hand instrumentation. The flexibility of nickeltitanium rotary instruments facilitates shaping of curved canals and enables the clinician to instrument canals to the desired tapered form with a high degree of consistency.

The antimicrobial effectiveness of instrumenting canals with rotary nickeltitanium instruments is in line with the results seen with manual instrumentation of root canals. Thus, instrumentation with either stainless steel or nickel-titanium rotary instruments in the presence of $\mathrm{NaOCl}$ renders canals free of bacteria in half to three quarters of cases.

A recent in vivo study that applied correlative light and electron microscopic techniques to evaluate residual intracanal infection after instrumentation with stainless steel hand files in mesiobuccal canals and NiTi instruments in mesiolingual canals of the same lower molars showed that there was no difference in their respective ability to eliminate infection. Bacteria cannot be completely eliminated after thorough instrumentation and irrigation regardless of the technique need to follow instrumentation with an anti- bacterial dressing before obturation to better achieve the goal of bacteria-free root canals.

\section{ANTIMICROBIAL EFFECT OF CHEMICAL AGENTS}

The antibacterial effect of mechanical preparation with saline as an irrigant has been shown to be inefficient in the elimination of bacteria from the root canal. This implies that mechanical instrumentation of the canal must be supplemented by antibacterial irrigants and dressings for efficient elimination of microorganisms from the root canal. There are many other benefits to be gained by the use of chemical agents during the preparation of the root canal. The agents used for chemical disinfection can be separated into two types those used for irrigation during canal preparation and those used as an intracanal dressing between appointments.

\section{IRRIGATION}

Irrigation is used for the removal of tissue remnants and dentin debris during mechanical instrumentation of the root canal. The main benefits of using irrigants during the cleaning of the canal include wetting of the canal walls and removal of debris by flushing, destruction of micro- organisms, dissolution of organic matter, removal of smear layer and softening of dentine and cleaning in areas that are inaccessible to mechanical cleansing methods. 
Despite this rather simple objective there has been great controversy over the effectiveness of irrigation, the fluid to use, and the delivery system. Paired with an effective suction device, irrigation is today the most effective way of evacuating tissue debris from the canals.

Various irrigation fluids have been suggested for the irrigation of root canals during instrumentation. Theoretically, the required properties of an irrigation fluid may vary depending on the pulpal diagnosis. During vital pulp extirpation and root canal shaping, saline could serve as the transport vehicle for vital tissue debris and fresh dentin chips.

When the pulp has become necrotic and infected, however, there are a great number of tissue breakdown compounds as well as microbial metabolic products that require a better solvent. The most common irrigation fluid used is sodium hypochlorite. Commercially available sodium hypochlorite is manufactured by passing chlorine through $\mathrm{NaOH}$. Consequently, most standard preparations of sodium hypochlorite have a high content of alkali and therefore are highly alkaline. Dakin described the proper way of preparing a non-irritating sodium hypochlorite solution relatively free of alkali. Unfortunately, this method has been forgotten and today, the common method for obtaining sodium hypochlorite for patient care is to purchase laundry bleach. In some instances, this bleach is diluted with water. This lowers the hypochlorite concentration but does not substantially lower the $\mathrm{pH}$. For some $\mathrm{pH}$ adjustments during dilution, $1 \%$ sodium bicarbonate may be used as the diluent. To obtain satisfactory tissue dissolution during instrumentation there is no compelling reason to use sodium hypochlorite at any concentration above $0.5 \%$. Sodium hypochlorite is also a very potent antimicrobial agent, totally killing enterococci at $0.5 \%$.
The chelating agent ethylenediamine tetraacetic acid (EDTA) is commonly used as an irrigant in conjunction with $\mathrm{NaOCl}$ solution, because EDTA is highly effective in removal of the smear layer and opening dentinal tubules, which potentiates the reach of antimicrobial irrigation and dressing. Citric acid and EDTA have been suggested as auxiliary irrigation aids to remove the smear layer that develops during the mechanical root canal preparation. Both these regimens are effective in removing the smear layer,but acidic solutions tend to more aggressively demineralize the dentin surface. It has been shown in vitro that removal of the smear layer facilitates the penetration into dentin and killing of microbes by intracanal disinfectants After the Second World War, quaternary ammonium compounds became very popular for wound treatments as they were believed to be very effective and to have very low toxicity. They soon became popular for root canal irrigation at concentrations between $0.1 \%$ and $1 \%$. Later, it became known that the antimicrobial effect in living tissue was sharply inhibited by tissue proteins and that the tissue toxicity was higher than earlier expected. This led to a decline in the use of quaternary ammonium compounds for endodontic irrigation, although they are still being used. Being detergents, quaternary ammonium compounds clean fatty tissue deposits.

Sterile saline has also been suggested as an irrigant but its usefulness is questionable. Saline does not support cleaning as it does not have a low surface tension like quaternary ammonium compounds or the ability to enhance tissue dissolution like sodium hypochlorite. Furthermore, having no antimicrobial effect it will not support the maintenance of asepsis during treatment, allowing cross-contamination.

Chlorhexidine, an antimicrobial agent with strong affinity to dental hard tissues, has recently been the object of some interest. It does not have any properties making it useful 
for debridement of root canals. However, due to its affinity to hard tissue, it has been suggested that the chlorhexidine would be retained and contribute to the maintenance of a bacteria-free root canal for some time after completed endodontic therapy.

According to a study, chlorhexidine has an excellent efficacy against $\mathrm{E}$. faecalis, because in the total of 10 canals incubated with this bacterial strain and then treated with chlorhexidine, no further bacteria could be detected in $100 \%$ of cases. Chlorhexidine completely inhibits the growth of E. faecalis. Furthermore, chlorhexidine proved to be effective even at low concentrations against the microorganisms most frequently present in infected root canals, anaerobic bacteria, and Candida albicans.

Apart from the positive antimicrobial efficacy of chlorhexidine discussed here, it important that $0.1 \%$ to $2 \%$ chlorhexidine solutions are classified as toxicologically safe. A $2 \%$ chlorhexidine solution has also been used as a sub gingival irrigant without adverse effects. Because of its cationic properties, chlorhexidine can bind to the hydroxyapatite of the dentin, and a gradual release of this bound chlorhexidine may protect the canal against microbial colonization beyond the actual medication period.

Aloe vera gel has mild antibacterial effect against E. faecalis, S. aureus and S. mutans. It has low antibacterial potency compared to propolis. The hydroalcoholic extract of propolis have a good anti-microbial agent against $\mathrm{E}$. faecalis especially following direct contact to this germ. Both tested natural substances have less antibacterial activity compared to Chlorhexidine, however their potency could be significantly increased by improvement in the extraction techniques.

Improved techniques of using these two could potentially lead to root canal antibacterial with fewer side effects.
There are many regions of the root canal system that are simply inaccessible to mechanical instrumentation and all of these areas have the potential to harbor microorganisms and necrotic pulp tissue. These areas include accessory canals, fins and webs that branch from the main canal or canals. Areas that are inaccessible to mechanical instrumentation can only be cleaned by antimicrobial irrigants that are able to permeate into these recesses. Any further antibacterial effect will only occur with the support of an intracanal dressing.

\section{DRESSINGS}

Mechanical cleaning, irrigation and dressing with antibacterial medicaments achieve a reduction of the number of living bacteria in infected root canals. Evaluation of the relative efficacy of these measures in eliminating the bacteria has shown that mechanical cleansing supported by irrigation significantly reduces the number of bacteria in the root canal, but that approximately 25 to 50 per cent of canals treated in this way still contain bacteria at the end of the appointment. The number of persisting bacterial cells is usually low, but these remaining bacteria can recover and rapidly increase in number between treatment visits if no antibacterial dressing is present in the root canal. The growth of bacteria between appointments can ultimately lead to the reestablishment of the number of bacteria that were initially present in the root canal before treatment.

The principal goal of dressing the root canal between appointments is to ensure a safe, antibacterial action with a long-lasting effect. If the active agent in the medicament is rapidly lost then the duration of its antibacterial activity is likely to be short, and thus ineffective. The antibacterial effect of dressing root canals with camphorated paramonochlorophenol(CMCP) and camphorated phenol has been assessed in vivo and been shown to be of limited efficacy. The 
clinical effectiveness of calcium hydroxide in infected canals has been tested in a number of in vivo studies and been shown to be an efficient antibacterial treatment eliminating micro- organisms in previously untreated cases from 75 per cent to more than 90 per cent of dressed canals. Application of an interappointment calcium hydroxide dressing prior to obturation has been shown to yield improved healing responses over non-calcium hydroxide treated teeth in human and animal teeth. Treatment with calcium hydroxide has also been shown to dissolve necrotic tissue and enhance the tissue dissolving effect of $\mathrm{NaOCl}$ solution.

It is critical that the calcium hydroxide dressing be placed carefully in the instrumented canal as a thick, moist paste fully filling the entire canal and that it be left for sufficient time to achieve the desired anti- microbial effect. The paste consistency helps prevent influx of the periapical fluid, which is an important nutrient source for any remaining bacterial cells. The hydroxyl ions that are responsible for the strong antibacterial effect are rapidly potent when in intimate contact with target microorganisms in vitro, but need time under in vivo conditions to diffuse into the adjacent dentine. The reason for the slow diffusion of hydroxyl ions into dentine is the powerful buffering capacity of dentine, which creates a concentration gradient across the root wall.

Dressing the canal for one week has been shown to be an efficient method in the clinical setting. After canal preparation and final irrigation, residual fluid should be aspirated leaving the canal walls moist since the antimicrobial effectiveness of calcium hydroxide depends on an aqueous environment. Calcium hydroxide is easily applied as a paste into the canal with a spiral paste filler. Any residual calcium hydroxide on the walls of the access cavity should be carefully removed before the temporary filling is placed. A well placed temporary filling of \&gt; $4 \mathrm{~mm}$ depth is essential, for without it the many antibacterial steps preceding its placement are rapidly undone.

\section{ROOT CANAL SEALER:}

The reason for failure in endodontics is due partly to the canal spaces not being obturated adequately. When communication exists between the internal and external environment, or when residual bacteria remains from inadequate cleaning and shaping, the antimicrobial activity of various components of sealers plays an important role in the success of endodontic treatment.

According to a study, different reagents of different sealer showed varying levels of effectiveness against $\mathrm{E}$. faecalis through the zones of inhibition. Roth 811 showed the greatest zones of inhibition with the mean of $1.1 \mathrm{~mm}$, followed by Sealapex with mean of $0.8 \mathrm{~mm}$, and Kerr EWT of $0.5 \mathrm{~mm}$. AH-Plus showed no zone of inhibition. Roth 811, a ZOE-based sealer, showed greatest antimicrobial effect against $E$. faecalis.

Fuss et al. also found Roth cement to have a more potent antimicrobial activity than calcium hydroxide sealer, Sealapex, after a 24$\mathrm{h}$ period. The antimicrobial effect of zinc-oxide eugenol cement was due to the action of eugenol. The reason for the calcium hydroxide sealer, Sealapex, being less effective against E. faecalis may be its low solubility of hydroxyl ion.

According to Barry and Thornsberry the size of zones of inhibition not only depends on the toxicity of the material but also its diffusibility and the rate of diffusibility. This could also explain the difference between the zones of inhibition of Roth 811 and Kerr EWT, both of which have eugenol in their ingredients.

Bystrom and Sundqvist also found that for calcium hydroxide sealer to be an effective antimicrobial agent, it should maintain a $\mathrm{pH}$ level greater than 12.5. As the calcium hydroxide sealer sets, the $\mathrm{pH}$ declines to approximately 9.14, causing it to lose 
effectiveness. AH-plus, a resin-based sealer, does not show any zone of inhibition. This could be because of the lack of release of formaldehyde.

According to Kaplan et al., the most effective antimicrobial sealers contain eugenol and formaldehyde. Without formaldehyde, $\mathrm{AH}-$ Plus sealer was absolutely ineffective against E. faecalis.

\section{PHOTO-ACTIVATED DISINFECTION (PAD)}

It is a novel method of disinfection for use in both caries removal and root canal treatment. The laser light is thought to be able to reach areas that are inaccessible with conventional techniques.

High-power lasers such as Nd: YAG and Er: YAG may induce periradicular necrosis and charring of dentinal tubules through generation of heat. Thus, the new method for eradication of microorganisms from the root canal is the application of low-power lasers.

PAD is an antimicrobial strategy in which lowenergy laser is used to activate a nontoxic photosensitizer like tolonium chloride, and the singlet oxygen released from these dyes damages the membranes and DNA of microorganisms. It has been recommended for use in root canal treatment as an alternative or supplement to other disinfection methods since it produces heat that is not clinically significant (less than $0.5^{\circ} \mathrm{C}$ ). In addition, photosensitizers have a high degree of selectivity to kill microorganisms without affecting the host cell viability. Application of PAD has shown to be successful in the eradication of multi-drugresistant microorganisms. According to a study by Fonseca et al., this method is very effective in eliminating E. faecalis from the root canal system.

\section{LASERS:}

Since most currently use of irrigants and intra canal medicaments have limited antibacterial spectrum and a limited ability to diffuse into the dentinal Tubules $(100 \mu \mathrm{m})$ therefore newer treatment strategies are considered to eliminate microbes from the root canal system which penetrate up to $1,110 \mu \mathrm{m}$. Laser light which penetrates up to $1000 \mu \mathrm{m}$ into the dentin thus has scope for complete canal sterilization. The laser is an effective tool for killing microorganisms because of the energy and wavelength characteristics. Numerous studies have documented that $\mathrm{CO} 2, \mathrm{Nd}$ : YAG, Argon, $\mathrm{XeCl}(308 \mathrm{~nm}), \mathrm{Er}, \mathrm{Cr}: Y S G G$ and Er: YAG laser irradiation has the the ability to kill the bacteria, remove debris and smear layer from the root canal walls following biomechanical instrumentation.175 But lasers which can be delivered through extremely fine flexible fiber optic systems and which can penetrate dentin to a depth that can eliminate bacteria are applicable. This particularly includes lasers in the near infrared region. Laser light in near infra-red region is absorbed by dentin only to a small extent. For complete elimination of bacteria within the tubules, light should penetrate deep without interaction with the superficial dentin. Nd: YAG and diode laser wavelengths are not absorbed in hard dental tissue and are thus able to be effective in deep layers. The Er: YAG laser acquires its efficiency by photoablative effect. The antibacterial effect of Er: YAG is effective but restricted to a small area surrounding the root canal.

\section{References}

1. 1.Nair PN. Pathogenesis of apical periodontitis and the causes of endodontic failures. Crit Rev Oral Biol Med. 2004 Nov; 15(6):348-81.

2. 2.Nair PN. Apical periodontitis: a dynamic encounter between root canal infection and host response. Periodontol 2000. 1997 Feb;13(1):121-48.

3. 3.Silva L, Nelson-Filho P, Leonardo MR, Rossi MA, Pansani CA. Effect of calcium hydroxide on bacterial endotoxin in vivo. J Endod. 2002 Feb;28(2):94-8. 
4. 4.Mohammadi Z, Dummer PM. Properties and applications of calcium hydroxide in endodontics and dental traumatology. Int Endod J. 2011 Aug;44(8):697-730.

5. 5.Noiri Y, Katsumoto T, Azakami H, Ebisu S. Effects of Er:YAG laser irradiation on biofilm-forming bacteria associated with endodontic pathogens in vitro. J Endod. $2008 \mathrm{Jul} ; 34(7): 826-9$.

6. 6.Herrera DR, Santos ZT, Tay LY, Silva EJ, Loguercio AD, Gomes BP. Efficacy of different final irrigant activation protocols on smear layer removal by EDTA and citric acid. Microsc Res Tech. 2013 Apr;76(4):364-9.

7. 7.Plotino G, Cortese $\mathrm{T}$, Grande NM, Leonardi DP, Di Giorgio G, Testarelli L et al. New technologies to improve root canal disinfection. Braz Dent J. 2016 JanFeb;27(1):3-8.

8. 8.Khademi AA, Mohammadi Z, Havaee A. Evaluation of the antibacterial substantivity of several intra-canal agents. Aust Endod J. 2006 Dec;32(3):112-5.

9. 9.Flemming H.C., Wingender J., Szewzyk U., Steinberg P., Rice S.A., Kjelleberg S.
Biofilms: An emergent form of bacterial life. Nat. Rev. Microbiol. 2016;14:563575.

10. 10.Diaz P.I. Microbial diversity and interactions in subgingival biofilm communities. Front. Oral Biol. 2012;15:17-40

11. 11.Dunavant T.R., Regan J.D., Glickman G.N., Solomon E.S., Honeyman A.L. Comparative evaluation of endodontic irrigants against Enterococcus faecalis biofilms. J. Endod. 2006;32:527-531.

12. 12.Zehnder M., Belibasakis G.N. On the dynamics of root canal infections-what we understand and what we don't. Virulence. 2015;6:216-222.

13. Gilbert P., Maira-Litran T., McBain A.J., Rickard A.H., Whyte F.W. The physiology and collective recalcitrance of microbial biofilm communities. Adv. Microb. Physiol. 2002;46:202-256.

14. 14.Wuertz S., Okabe S., Hausner M. Microbial communities and their interactions in biofilm systems: An overview. Water Sci. Technol. 2004;49: 327-336 